LETTER TO THE EDITOR

\title{
Orbital phlegmona from upper eyelid chalazion
}

\author{
Trnavec $\mathrm{B}^{1}$, Vodrazkova $\mathrm{E}^{1,2}$, Cernak $\mathrm{A}^{1}$ \\ Department of Ophthalmology Medical Faculty SMU, Hospital of Ss. Cyril and Methodius Bratislava. \\ btrnavec@post.sk
}

Text in PDF www.elis.sk

In progression of orbital infection, the patient is at risk of intracranial complications (purulent meningitis, brain abscess, cavernous sinus thrombosis). Intracranial complications are potentially life threatening, thus the patients with suspected infection of the orbit have to be admitted to hospital and the eye examinations, CT of orbits, sinuses and brain have to be performed. CT examination reveals the extent and origin of a disease and the correct diagnosis can be obtained.

Patients with the bacterial infection of the orbit must be immediately treated with broad-spectrum antibiotics in sufficient doses, and, if the abscess is found, a surgical treatment has to be indicated (1).

We have the patient, who developed orbital phlegmona by transmission from the upper eyelid chalazion, which is among the rare causes of the orbital phlegmona. Urgent computed tomography (CT) of the orbit confirmed the correct diagnosis and an immediate treatment with broad-spectrum antibiotics prevented a disease progression.

The urgent CT has an irreplaceable role in determining the correct early diagnosis $(1,2)$.

Thanks to urgent CT of the orbit in our patient (Fig. 1a, b), the correct diagnosis of orbital phlegmona was made and an immedi-

${ }^{1}$ Department of Ophthalmology Medical Faculty SMU, Hospital of Ss. Cyril and Methodius, Bratislava, and ${ }^{2}$ St.Elizabeth University of Health and Social Sciences, Bratislava, Slovakia

Address for correspondence: B. Trnavec, MD, Department of Ophthalmology Medical Faculty SMU, Hospital of Ss. Cyril and Methodius, Antolska 11, SK-851 07 Bratislava, Slovakia.
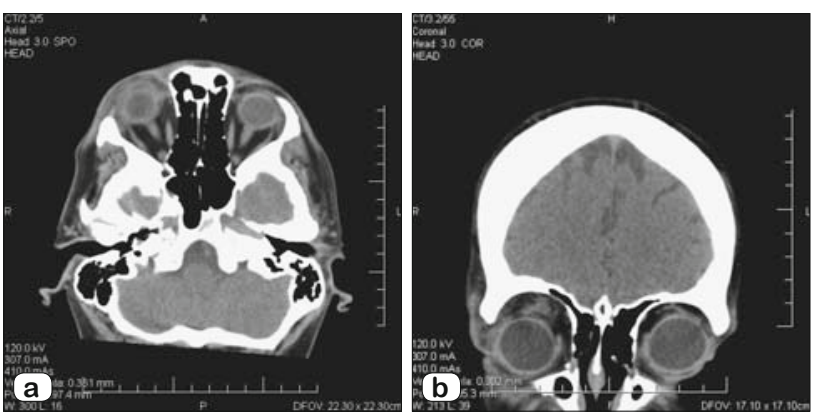

Fig. 1. CT image of orbits: inflammatory infiltrate of the upper eyelid with propagation under the ceiling of the orbit with thickening of the superior rectus muscle and inflammatory infiltration of right lacrimal gland. a) axial scan, b) coronar scan.

ate treatment with cephalosporin antibiotics was initiated. Early antibiotic treatment in a sufficient dose prevented disease progression, patient's ocular finding rapidly improved, no complications occurred. Immunological examination of the patient was negative.

\section{References}

1. Šuchaň M, Horňák M, Kaliarik L, Krempaská S, Koštialová T, Koval' J. Orbital complications of sinusitis. Cesk Slov Oftalmol 2014; 70 (6): 234-238.

2. Mouriaux F, Rysanek B, Babin E, Cattoir V. Orbital cellulitis. J Fr Ophtalmol 2012; 35 (1): 52-57. doi: 10.1016/j.jfo.2011.08.004

Received August 12, 2015. Accepted August 21, 2015. 